\title{
Solving Highly Nonlinear Partial Differential Equations Using Homotopy Perturbation Method
}

\author{
Amanat Ali Khan ${ }^{1, ~ *, ~ M u s a m m e t ~ T a h m i n a ~ A k t e r ² ~}$ \\ ${ }^{1}$ Department of Mathematics, Cuet College, Chattogram, Bangladesh \\ ${ }^{2}$ Department of Mathematics, Chittagong University of Engineering \&Technology, Chattogram, Bangladesh \\ Email address: \\ amanat@gmail.com(A. A. Khan), tahmina13@cuet.ac.bd(M. T. Akter) \\ ${ }^{*}$ Corresponding author
}

To cite this article:

Amanat Ali Khan, Musammet Tahmina Akter. Solving Highly Nonlinear Partial Differential Equations Using Homotopy Perturbation Method. American Journal of Applied Mathematics. Vol. 8, No. 6, 2020, pp. 334-343. doi: 10.11648/j.ajam.20200806.16

Received: November 12, 2020; Accepted: November 26, 2020; Published: December 11, 2020

\begin{abstract}
An elegant and powerful technique is Homotopy Perturbation Method (HPM) to solve linear and nonlinear ordinary and partial differential equations. The method, which is a coupling of the traditional perturbation method and homotopy in topology, deforms continuously to a simple problem which can be solved easily. The method does not depend upon a small parameter in the equation. Using the initial conditions this method provides an analytical or exact solution. From the calculation and its graphical representation it is clear that how the solution of the original equation and its behavior depends on the initial conditions. Therefore there have been attempts to develop new techniques for obtaining analytical solutions which reasonably approximate the exact solutions. Many problems in natural and engineering sciences are modeled by nonlinear partial differential equations (NPDEs). The theory of nonlinear problem has recently undergone much study. Nonlinear phenomena have important applications in applied mathematics, physics, and issues related to engineering. In this paper we have applied this method to Burger's equation and an example of highly nonlinear partial differential equation to get the most accurate solutions. The final results tell us that the proposed method is more efficient and easier to handle when is compared with the exact solutions or Adomian Decomposition Method (ADM).
\end{abstract}

Keywords: Homotopy Perturbation Method, Burger's Equation, Nonlinear Partial Differential Equations, Approximate Solutions, Adomian Decomposition Method

\section{Introduction}

To investigate of the numerical and exact solutions for nonlinear partial differential equations (NLPDEs) plays an important role in the study of nonlinear physical phenomena [1]. Nonlinear wave phenomena appear in various scientific and engineering fields such as fluid mechanics, plasma physics etc. The dispersion, dissipation, diffusion, reaction and convection of nonlinear wave phenomena are very important in nonlinear wave equations [2]. In the past several decades, there have been significant improvements in study of exact solutions. Recently many researcher mainly had paid attention to obtain solutions of NLPDEs by applying various methods [3-5]. The main purpose of this paper was to apply homotopy perturbation method (HPM) to Burger's equation [6] and also a highly nonlinear partial differential equation compared with Adomian Decomposition Method (ADM) [7]. Burgers' Equation is nonlinear partial differential equation which is used in various fields of physical phenomena such as boundary layer behavior, shock weave formation, turbulence, the weather problem, mass transport, traffic flow and acoustic transmission. The Burger's model of turbulence is a very important fluid dynamic model and the study of this model and the theory of shock waves have been considered by many authors, both to obtain a conceptual understanding of a class of physical flows and for testing various numerical methods [8]. The general form of Burger's equation is the simplest mathematical formulation of the competition between nonlinear advection and viscous diffusion.

The Homotopy Perturbation Method was first introduced by the Chinese researcher Dr. Ji Huan He in 1998 [9] for solving linear and nonlinear differential and integral equations. This method is the combination of the traditional 
perturbation and the homotopy method $[10,11]$. So it takes the full advantage of both methods. In this method the solution is considered as the summation of an infinite series which usually converges very rapidly to accurate the solutions [12]. The HPM is a universal one which can solve various kinds of nonlinear equations [13-15]. This method is a hefty mathematical tool which is such a useful promising method that can solve any linear or nonlinear PDE of fractional order [16, 17]. The HPM has been used by many mathematicians, engineers, authors and researchers to solve various functional equations. Some examples, Ji-Huan He in 1999 [18] used the HPM for solving nonlinear ordinary differential equations (NODEs) of the first and second orders, J. He in 2003 [19] solved the NODEs with nth order, J. He in 2004 [20] by HPM found out the solution of the oscillator equation, J. He studied the HPM for finding the periodic solutions and bifurcations of delay-differential equations, in 2005 [21]. Also this method is successfully applied to boundary value problems [22], the system of coupled Burger's equation [23] and to other fields. In addition it does not need small parameters in the equations so that the limitations of the traditional perturbations can be eliminated and the calculations involved in HPM are very simple and straight forward. On the other side it is analyzed that, in the aforementioned method (ADM) [24, 25, 26], first Adomian polynomials are calculated, which is a bit difficult task and time consuming process and the fact that the HPM solves nonlinear problems without using Adomian's polynomials is a clear advantage of this technique over the Adomian Decomposition Method (ADM). The comparative study between these two methods shows that the results obtained by using Homotopy Perturbation Method (HPM) with a special convex constructed Homotopy is almost equivalent to the results obtained by using Adomian Decomposition Method (ADM) for these types of nonlinear problems [27, 28]. Also when we compare between the exact solution and the approximate solution, we see that the difference between these two solutions is very small. i. e., the approximate solutions obtained by HPM are most accurate and smooth. Also we get the better exact solutions using HPM and that approves the proficiency of this method for exact and approximate solutions. In the following, we shall illustrate the HPM introduced by $\mathrm{J} \mathrm{He}$ and its applications. This paper is arranged as follows: In section- 2 the basic ideas of HPM is presented. The efficiency of this method is verified by the numerical results for two examples in section-3 and the conclusion will appear in section-4.

\section{Basic Ideas of Homotopy Perturbation Method (HPM)}

To illustrate the basic ideas of the method we consider the following ordinary or partial differential equation of order $n$.

$$
A(u)-f(r)=0, r \in \Omega, \text { where } u=g(x, t)
$$

with the boundary conditions:

$$
\mathrm{B}\left(\mathrm{u}, \frac{\partial \mathrm{u}}{\partial \mathrm{n}}\right)=0, \mathrm{r} \in \Gamma
$$

and initial conditions:

$$
\frac{\hat{\sigma}^{\lambda}}{\partial \mathrm{t}^{\lambda}} \mathrm{u}(\mathrm{x}, 0)=\Psi_{\lambda}(\mathrm{x}), \lambda=0,1,2, \ldots \ldots \mathrm{n}-1 .
$$

where $\mathrm{A}$ is a general differential operator, $\mathrm{u}$ is an unknown function, $\mathrm{f}$ is a known analytical function. $\mathrm{x}$ and $\mathrm{t}$ denote spatial and temporal independent variables respectively. B is the boundary operator, $\Gamma$ is the boundary of the domain $\Omega$. The operator A can be decomposed into two operators $L$ and $\mathrm{N}$; i.e, $\mathrm{A}=\mathrm{L}+\mathrm{N}$, where $\mathrm{L}$ is a simple part which is easy to choose and it is also linear part and $\mathrm{N}$ contains the remaining part of $\mathrm{A}$; the part $\mathrm{N}$ may be linear or nonlinear part of $\mathrm{A}$.

Equation (1) can be rewritten as follows:

$$
\mathrm{L}(\mathrm{u})+\mathrm{N}(\mathrm{u})-\mathrm{f}(\mathrm{r})=0
$$

By the homotopy technique we construct a Homotopy $(\mathrm{H})$ as $\mathrm{V}: \Omega \times[0,1] \longrightarrow \mathrm{R}$ defined by

$$
\mathrm{H}(\mathrm{V}, \mathrm{p})=(1-\mathrm{p})\left[\mathrm{L}(\mathrm{V})-\mathrm{L}\left(\mathrm{u}_{0}\right)\right]+\mathrm{p}[\mathrm{A}(\mathrm{V})-\mathrm{f}(\mathrm{r})]
$$

where $\mathrm{R}$ is the set of real numbers.

The above homotopy (5) satisfies the following equation:

$$
\begin{gathered}
\mathrm{H}(\mathrm{V}, \mathrm{p})=(1-\mathrm{p})\left[\mathrm{L}(\mathrm{V})-\mathrm{L}\left(\mathrm{u}_{0}\right)\right] \\
+\mathrm{p}[\mathrm{A}(\mathrm{V})-\mathrm{f}(\mathrm{r})]=0
\end{gathered}
$$

Equivalently (6) can be rewritten as follows:

$$
\mathrm{L}(\mathrm{V})-\mathrm{L}\left(\mathrm{u}_{0}\right)+\mathrm{p}\left[\mathrm{N}(\mathrm{V})+\mathrm{L}\left(\mathrm{u}_{0}\right)-\mathrm{f}(\mathrm{r})\right]=0
$$

where $p \in[0,1]$ is an embedding parameter and $\mathrm{u}_{0}$ is the first initial approximation guess for the solution of (1), which satisfies the given initial or boundary conditions.

Obviously from (6) we will have,

$$
\mathrm{H}(\mathrm{V}, 0)=\mathrm{L}(\mathrm{V})-\mathrm{L}\left(\mathrm{u}_{0}\right)=0
$$

and

$$
\mathrm{H}(\mathrm{V}, 1)=\mathrm{A}(\mathrm{V})-\mathrm{f}(\mathrm{r})=0
$$

On changing the value of $\mathrm{p}$ from zero to unity, $\mathrm{V}$ changes from $\mathrm{u}_{0}$ to $\mathrm{u}$. In topology it is called the deformation and also $\mathrm{L}(\mathrm{V})-\mathrm{L}\left(\mathrm{u}_{0}\right)$ of $(8)$ and $\mathrm{A}(\mathrm{V})-\mathrm{f}(\mathrm{r})$ of $(9)$ are called the homotopic. According to HPM we can assume that the solution of (6) or (7) as a following power series in P.

$$
\mathrm{V}=\sum_{\mathrm{i}=0}^{\infty} \mathrm{p}^{\mathrm{i}} \mathrm{V}_{\mathrm{i}}=\mathrm{V}_{0}+\mathrm{p} \mathrm{V}_{1}+\mathrm{P}^{2} \mathrm{~V}_{2}+\mathrm{p}^{3} \mathrm{~V}_{3}+\mathrm{p}^{4} \mathrm{~V}_{4}+\ldots \ldots
$$

The embedding parameter $p \in[0,1]$ is considered as an expanding parameter and the solution of (1) for $p=1$ can be expressed as:

$$
\mathrm{u}=\operatorname{Lim}_{\mathrm{p} \rightarrow \mathrm{l}} \mathrm{V}=\mathrm{V}_{0}+\mathrm{V}_{1}+\mathrm{V}_{2}+\mathrm{V}_{3}+\mathrm{V}_{4}+\mathrm{V}_{5}+\cdots \cdots \cdots
$$

The following opinions are suggested by J. He to ensure that the convergence of the infinite series given by (11). The 
series (11) is convergent for most cases but the rate of convergence depends on the nonlinear part $\mathrm{N}(\mathrm{u})[12,18,29]$.

(i). The second derivative of $\mathrm{N}(\mathrm{u})$ with respect to $\mathrm{u}$ must be small.

(ii). The norm of $\mathrm{L}^{-1} \frac{\partial \mathrm{N}}{\partial \mathrm{u}}$ must be smaller than one so that the series converges.

\section{Applications}

In this section we apply HPM for two examples and compared our results with exact and ADM solutions respectively. The errors between exact and homotopy solutions are denoted by

$\phi_{\mathrm{n}}=\sum_{\mathrm{i}=0}^{\mathrm{n}-1} \phi_{\mathrm{i}}$, where $\phi_{\mathrm{n}}$ are the approximate solutions obtained by the HPM.

$$
\begin{gathered}
\mathrm{H}(\mathrm{V}, \mathrm{p})=(1-\mathrm{p})\left(\frac{\partial^{2}}{\partial \mathrm{x}^{2}} \mathrm{~V}-\frac{\partial^{2}}{\partial \mathrm{x}^{2}} \mathrm{u}_{0}\right)+\mathrm{p}\left(\frac{\partial^{2}}{\partial \mathrm{x}^{2}} \mathrm{~V}(\mathrm{x}, \mathrm{t})-\frac{1}{\delta} \mathrm{V}(\mathrm{x}, \mathrm{t}) \frac{\partial}{\partial \mathrm{x}} \mathrm{V}(\mathrm{x}, \mathrm{t})-\frac{1}{\delta} \frac{\partial}{\partial \mathrm{t}} \mathrm{V}(\mathrm{x}, \mathrm{t})\right)=0 \\
\text { or, } \frac{\partial^{2}}{\partial \mathrm{x}^{2}} \mathrm{~V}-\frac{\partial^{2}}{\partial \mathrm{x}^{2}} \mathrm{u}_{0}+\mathrm{p} \frac{\partial^{2}}{\partial \mathrm{x}^{2}} \mathrm{u}_{0}-\frac{\mathrm{P}}{\delta} \mathrm{V} \frac{\partial}{\partial \mathrm{x}} \mathrm{V}-\frac{\mathrm{P}}{\delta} \mathrm{V} \frac{\partial}{\partial \mathrm{t}} \mathrm{V}=0,
\end{gathered}
$$

where $\mathrm{u}_{0}$ is the first initial approximation for the solution of (12), which satisfies the given boundary conditions (13) and selected by

$$
L(u)=\frac{\partial^{2}}{\partial x^{2}} u, N(u)=u \frac{\partial}{\partial x} u-\delta \frac{\partial^{2}}{\partial x^{2}} u(x, t) \& f(r)=f(x, t)=0
$$

We can assume that the solution of (15) according to HPM can be expressed as a power series in $\mathrm{p}$ as follows:

$$
\mathrm{V}=\sum_{\mathrm{i}=0}^{\infty} \mathrm{p}^{\mathrm{i}} \mathrm{V}_{\mathrm{i}}=\mathrm{V}_{0}+\mathrm{p} \mathrm{V}_{1}+\mathrm{p}^{2} \mathrm{~V}_{2}+\mathrm{p}^{3} \mathrm{~V}_{3}+\mathrm{p}^{4} \mathrm{~V}_{4}+\ldots \ldots
$$

By the HPM, the approximate solution of (12), therefore can be readily obtained by

$$
\mathrm{u}=\underset{\mathrm{p} \rightarrow \mathrm{l}}{\operatorname{Lim} \mathrm{V}}=\mathrm{V}_{0}+\mathrm{V}_{1}+\mathrm{V}_{2}+\mathrm{V}_{3}+\mathrm{V}_{4}+\mathrm{V}_{5}
$$

Taking the solution of (15) similar to the form (16) and substituting (16) into (15) and equating the coefficients of the like terms with the identical powers of $p$ leads to the following equations:

$$
\begin{gathered}
\mathrm{p}^{0}: \frac{\partial^{2}}{\partial \mathrm{t}^{2}} \mathrm{~V}_{0}-\frac{\partial^{2}}{\partial \mathrm{t}^{2}} \mathrm{u}_{0}=0 \\
\mathrm{p}^{1}: \delta \frac{\partial^{2}}{\partial \mathrm{x}^{2}} \mathrm{~V}_{1}+\delta \frac{\partial^{2}}{\partial \mathrm{x}^{2}} \mathrm{u}_{0}-\mathrm{V}_{0} \frac{\partial}{\partial \mathrm{x}} \mathrm{V}_{0}-\frac{\partial}{\partial \mathrm{t}} \mathrm{V}_{0}=0
\end{gathered}
$$$$
V_{2}=-\frac{\pi^{6} x^{5}}{240 \delta^{5} t^{6}}, V_{3}=\frac{17 \pi^{8} x^{7}}{40320 \delta^{7} t^{8}}, V_{4}=-\frac{31 \pi^{10} x^{9}}{725760 \delta^{9} t^{10}}
$$

and so on. (12).

$$
\begin{gathered}
\mathrm{p}^{2}: \delta \frac{\partial^{2}}{\partial \mathrm{x}^{2}} \mathrm{~V}_{2}-\frac{\partial}{\partial \mathrm{x}}\left(\mathrm{V}_{0} \mathrm{~V}_{1}\right)-\frac{\partial}{\partial \mathrm{t}} \mathrm{V}_{1}=0 \\
\mathrm{p}^{3}: \delta \frac{\partial^{2}}{\partial \mathrm{x}^{2}} \mathrm{~V}_{3}-\frac{\partial}{\partial \mathrm{x}}\left(\mathrm{V}_{0} \mathrm{~V}_{2}\right)-\mathrm{V}_{1} \frac{\partial}{\partial \mathrm{x}} \mathrm{V}_{1}=\frac{\partial}{\partial \mathrm{t}} \mathrm{V}_{2} \\
\mathrm{p}^{4}: \delta \frac{\partial^{2}}{\partial \mathrm{x}^{2}} \mathrm{~V}_{4}-\frac{\partial}{\partial \mathrm{x}}\left(\mathrm{V}_{0} \mathrm{~V}_{3}\right)-\frac{\partial}{\partial \mathrm{x}}\left(\mathrm{V}_{1} \mathrm{~V}_{2}\right)-\frac{\partial}{\partial \mathrm{t}} \mathrm{V}_{3}=0 \\
\mathrm{p}^{\mathrm{n}}: \frac{\partial^{2}}{\partial \mathrm{x}^{2}} \mathrm{~V}_{\mathrm{n}}-\frac{\partial}{\partial \mathrm{t}} \mathrm{V}_{\mathrm{n}-1}=\sum_{\mathrm{r}=0}^{\mathrm{n}-1} \mathrm{~V}_{\mathrm{r}} \frac{\partial}{\partial \mathrm{x}} \mathrm{V}_{\mathrm{n}-\mathrm{r}-1}
\end{gathered}
$$

According to the homotopy perturbation method let us consider the following homotopy
Solving above differential equations (19-23) and finding the unknown solution $\mathrm{u}(\mathrm{x}, \mathrm{t})$, we take the following initial guess $\mathrm{u}_{0}(\mathrm{x}, \mathrm{t})$ which satisfies the boundary conditions (13) of

$$
\mathrm{V}_{0}=\mathrm{u}_{0}=\frac{\mathrm{x}}{\mathrm{t}}-\frac{\pi^{2} \mathrm{x}}{2 \delta \mathrm{t}^{2}}
$$

Now under the boundary conditions $\mathrm{V}_{\mathrm{n}}(0, \mathrm{t})=\mathrm{V}_{\mathrm{nx}}(0, \mathrm{t})=$ $0,1 \leq \mathrm{n} \in \mathrm{N}$ for all equations(19-23), we get from (19),

$$
\mathrm{V}_{1}=\frac{\pi^{4} \mathrm{x}^{3}}{24 \delta^{3} \mathrm{t}^{4}}
$$

Similarly we get from the above equations (20-22): 
Therefore using (17) and the components of $\mathrm{V}_{\mathrm{n}}$, we get the approximate solution of (12) in a series form:

$$
\begin{aligned}
\mathrm{u}_{\text {app }} & =\mathrm{V}_{0}+\mathrm{V}_{1}+\mathrm{V}_{2}+\mathrm{V}_{3}+\mathrm{V}_{4}+\mathrm{V}_{5}+\mathrm{V}_{6}+\mathrm{V}_{7}+\mathrm{V}_{8}+\mathrm{V}_{9} \\
& =\frac{\mathrm{x}}{\mathrm{t}}-\frac{\pi^{2} \mathrm{x}}{2 \delta \mathrm{t}^{2}}+\frac{\pi^{4} \mathrm{x}^{3}}{24 \delta^{3} \mathrm{t}^{4}}-\frac{\pi^{6} \mathrm{x}^{5}}{240 \delta^{5} \mathrm{t}^{6}}+\frac{17 \pi^{8} \mathrm{x}^{7}}{40320 \delta^{7} \mathrm{t}^{8}}-\frac{31 \pi^{10} \mathrm{x}^{9}}{725760 \delta^{9} \mathrm{t}^{10}}+\frac{691 \pi^{12} \mathrm{x}^{11}}{159667200 \delta^{11} \mathrm{t}^{12}}-\frac{5461 \pi^{14} \mathrm{x}^{13}}{12454041600 \delta^{13} \mathrm{t}^{14}} \\
& +\frac{929569 \pi^{16} \mathrm{x}^{15}}{20922789888000 \delta^{15} \mathrm{t}^{16}}-\frac{3202291 \pi^{18} \mathrm{x}^{17}}{711374856192000 \delta^{17} \mathrm{t}^{18}}+\frac{221930581 \pi^{20} \mathrm{x}^{19}}{486580401635328000 \delta^{19} \mathrm{t}^{20}} .
\end{aligned}
$$

Which is the approximate solution of the nonlinear partial differential equation (12) for the boundary conditions (13). Also which is the same solution of nonlinear Burger's equation (12) that was achieved by Adomian Decomposition Method (ADM) for the same boundary conditions (13) [6]. Now we will compare the approximate solution (24) with the exact solution (14). Here the exact solution (14) can be verified by direct substitution into the Burgers' equation (12) for the boundary conditions (13). Here expanding the exact solution $\mathrm{u}(\mathrm{x}, \mathrm{t})$ in ascending powers of $\mathrm{x}$, we see that every successive term of expansion of $\mathrm{u}(\mathrm{x}, \mathrm{t})$ is the same component of every successive portion of the approximate solution in ascending powers of $\mathrm{x}$ respectively.

\subsubsection{Tables}

Table 1. HPM, Exact solutions and absolute errors of $u(x, t)$ at the time $t=$ 1.1 and the parameter $\delta=4.45$.

\begin{tabular}{llll}
\hline $\mathbf{x}_{\mathbf{i}}$ & Solutions by HPM & Exact & Absolute Errors \\
\hline 0.1 & -0.0007077540555861 & $-0.0007077540555861:$ & $2.11 \times 10^{-17}$ \\
0.2 & $-0.001227145398962 \varepsilon$ & $-0.0012271453989628:$ & $3.6 \times 10^{-17}$ \\
0.3 & $-0.001371357222003 ;$ & $-0.0013713572220037 ;$ & $1.1 \times 10^{-17}$ \\
0.4 & $-0.000956637642045 \&$ & $-0.0009566376420457:$ & $7.6 \times 10^{-17}$ \\
0.5 & $0.0001962342427974 ;$ & 0.00019623424279741 & $4.38 \times 10^{-17}$ \\
0.6 & $0.0022605597852225:$ & 0.00226055978522243 & $1.02 \times 10^{-16}$ \\
0.7 & $0.0054024319723415 ;$ & 0.00540243197234158 & $10^{-18}$ \\
0.8 & $0.0097795657769406:$ & 0.00977956577694061 & $10^{-17}$ \\
0.9 & $0.0155402637714919:$ & 0.01554026377149065 & $1.27 \times 10^{-15}$ \\
1.0 & $0.0228225294470131 !$ & 0.02282252944700169 & $1.15 \times 10^{-14}$ \\
\hline
\end{tabular}

Table 2. HPM, Exact solutions and absolute errors of $u(x, t)$ at the time $t=1$ and the parameter $\delta=3.5$.

\begin{tabular}{llll}
\hline $\mathbf{x}_{\mathbf{i}}$ & Solutions by HPM & Exact & $\begin{array}{l}\text { Absolute } \\
\text { Errors }\end{array}$ \\
\hline 0.1 & -0.04089976095412922 & -0.0408997609541292 & $2 \times 10^{-17}$ \\
0.2 & -0.0812338191297997 & -0.0812338191297997 & 0 \\
0.3 & -0.1204455204484999 & -0.1204455204484998 & $10^{-16}$ \\
0.4 & -0.1579960023888962 & -0.1579960023888961 & $10^{-16}$ \\
0.5 & -0.193372342772688 & -0.193372342772688 & 0 \\
0.6 & -0.2260948599420596 & -0.2260948599420599 & $3 \times 10^{-16}$ \\
0.7 & -0.255723356676044 & -0.255723356676052 & $8 \times 10^{-15}$ \\
0.8 & -0.2818621563825582 & -0.2818621563826897 & $1.315 \times 10^{-13}$ \\
0.9 & -0.3041638411547831 & -0.3041638411563245 & $1.5414 \times 10^{-12}$ \\
1.0 & -0.3223316626775547 & -0.3223316626914399 & $1.38852 \times 10^{-11}$ \\
\hline
\end{tabular}

\subsubsection{Graphical Representations}

The various exact solution and corresponding approximate solutions' figures are given below for the real values of the parameter $\delta$. We divided the graphs into two kinds; first kinds are three dimensional and other kinds are two-dimensional.

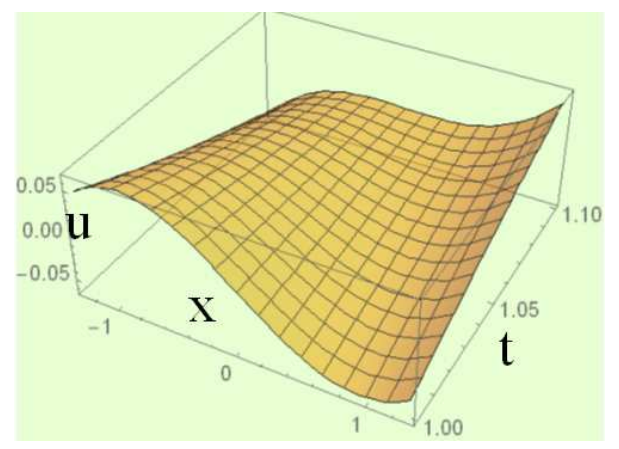

Figure 1. Exact Solution $x \in[-1.3,1.3]$ and $t \in[1,1.1]$.

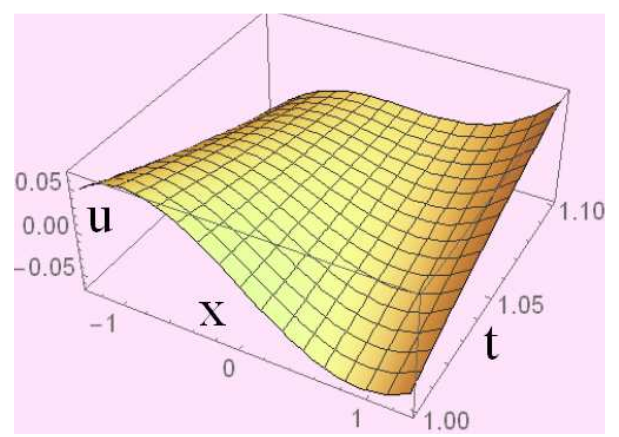

Figure 2. Approximate Solution $x \in[-1.3,1.3]$ and $t \in[1,1.1]$.

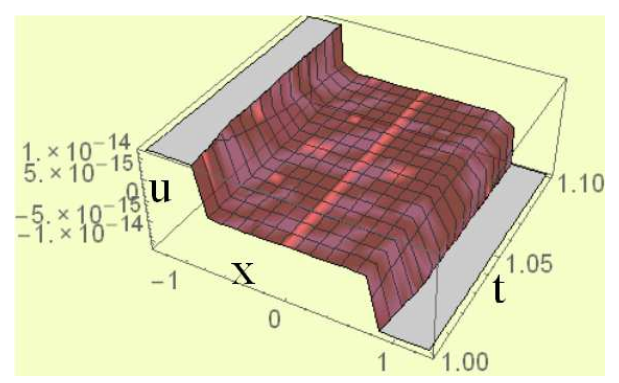

Figure 3. Error Solution $x \in[-1.3,1.3]$ and $t \in[1,1.1]$.

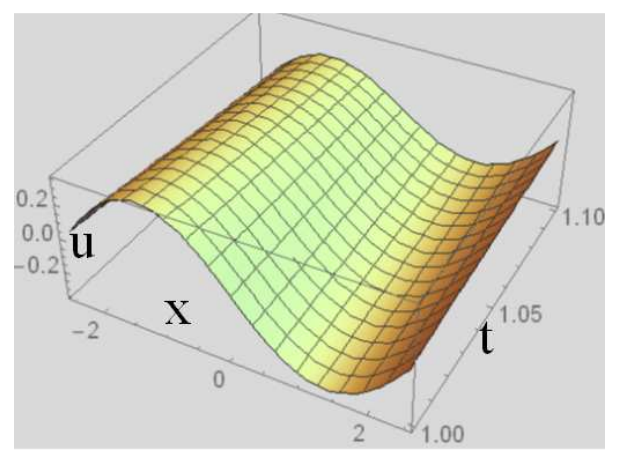

Figure 4. Exact Solution $x \in[-2.5,2.5]$ and $t \in[1,1.1]$. 


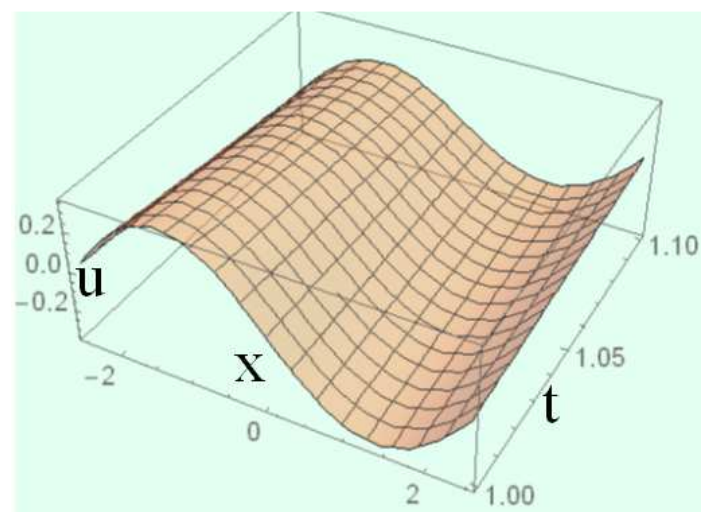

Figure 5. Approximate Solution $x \in[-2.5,2.5]$ and $t \in[1,1.1]$.

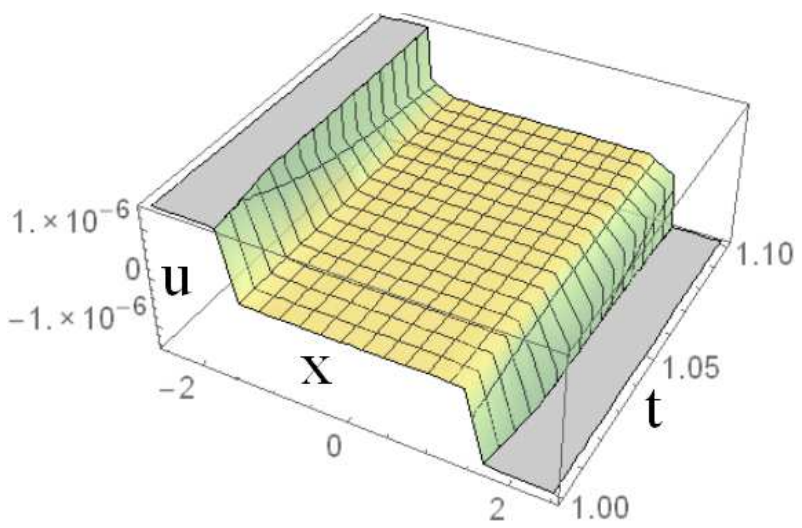

Figure 6. Error Solution $x \in[-2.5,2.5]$ and $t \in[1,1.1]$.

Now various two-dimensional graphs for exact solution, corresponding approximate solution and error solutions are given below for the real values of the parameter $\delta=4.45$ and $\delta=3.5$.

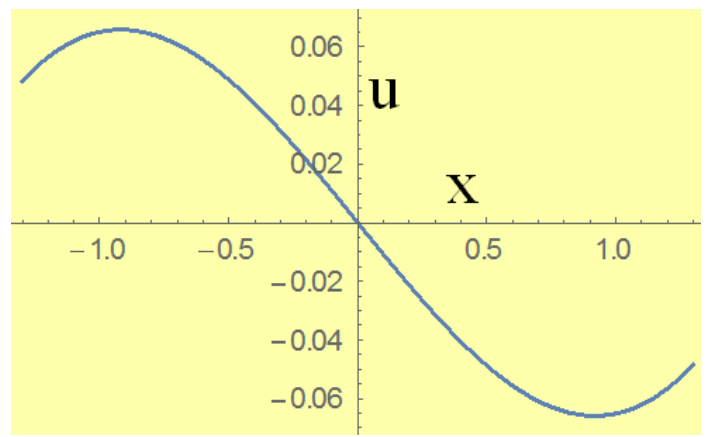

Figure 7. $x \in[-1.3,1.3]$

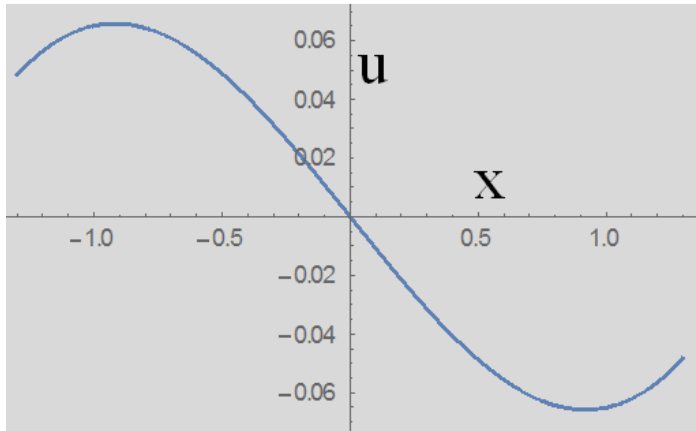

Figure 8. $x \in[-1.3,1.3]$.

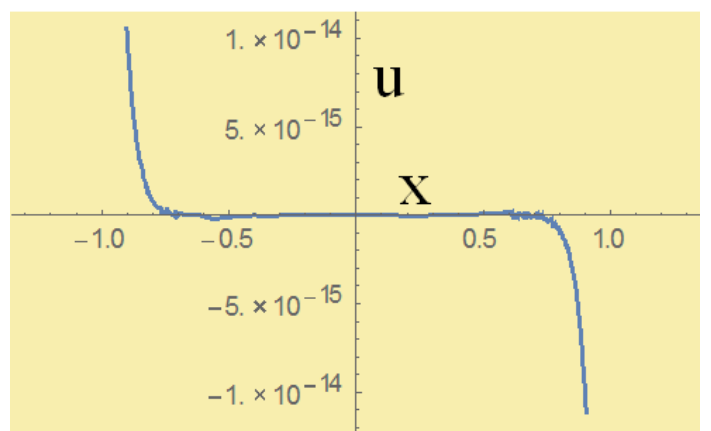

Figure 9. $x \in[-1.3,1.3]$

Figures 7, 8 and 9 show exact, approximate and error solutions for $\mathrm{t}=1$ and for the range $\mathrm{x} \in[-1.3,1.3]$ with $\delta=$ 4.45 .

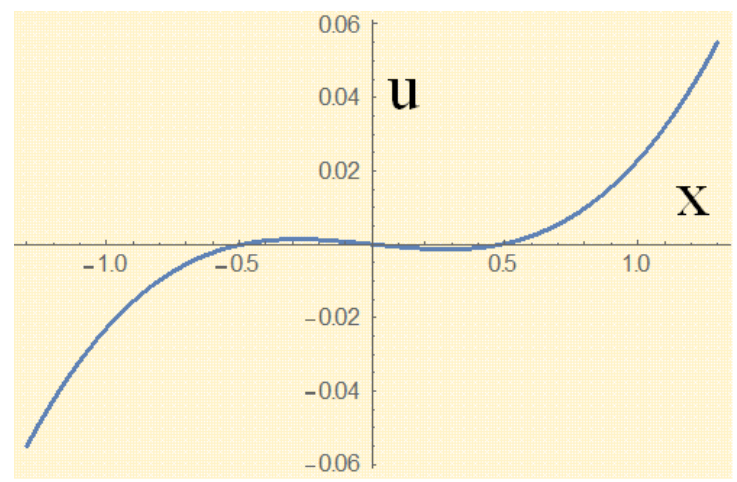

Figure 10. $x \in[-1.3,1.3]$.

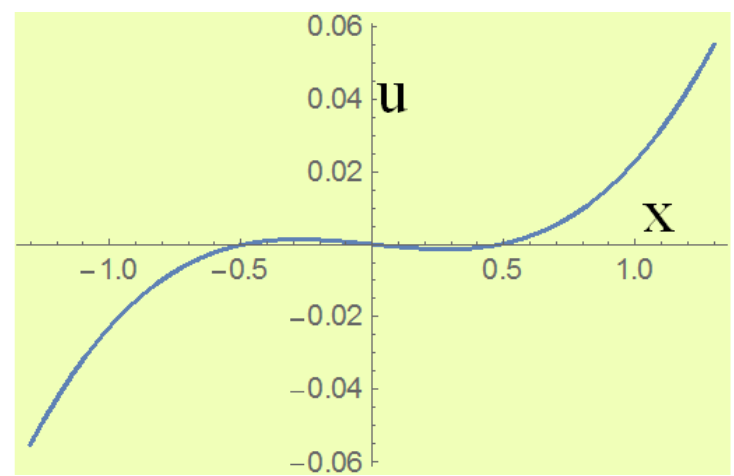

Figure 11. $x \in[-1.3,1.3]$.

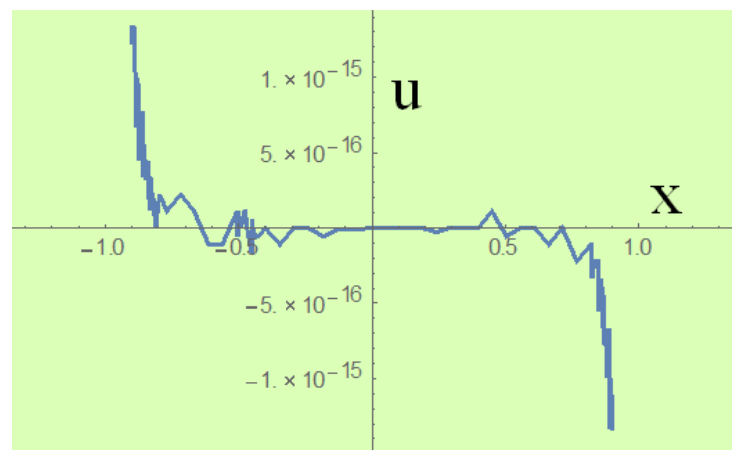

Figure 12. $x \in[-1.3,1.3]$.

Figures 10, 11 and 12 show exact, approximate and error solutions respectively for $\mathrm{t}=1.1$ and for the range $\mathrm{x} \in[-1.3$, 
1.3] with $\delta=4.45$.

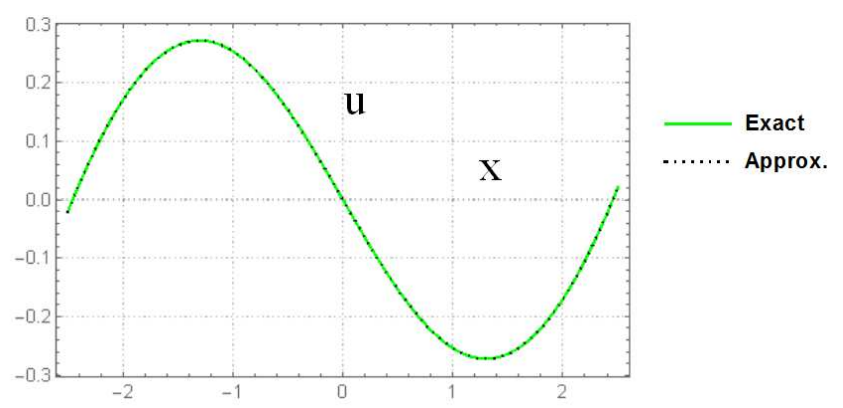

Figure 13. Shows the combined curves of the exact (solid curve) and the approximate solution (dotted curve) for $t=1.05$ and $x \in[-2.5,2.5]$ with $\delta=$ 3.5 .

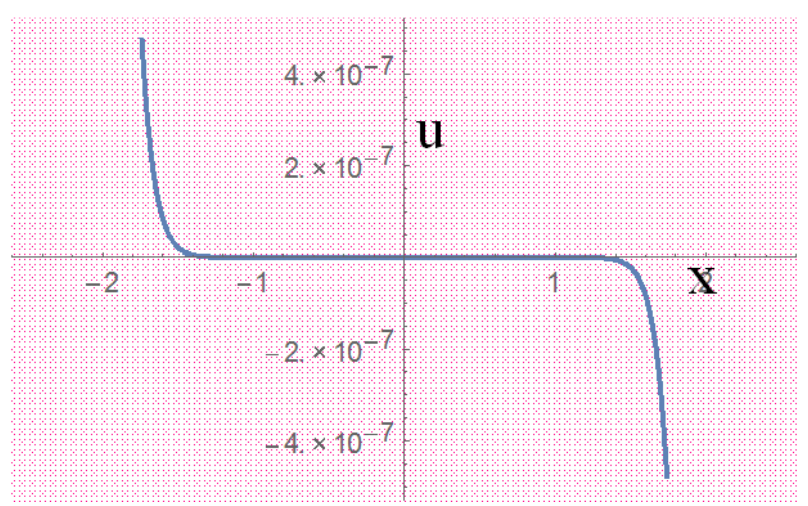

Figure 14. The result in the interval $x \in[-2.5,2.5]$ obtained for error solution for the $t=1.05$ and $\delta=3.5$.

\subsubsection{Results and Discussions of the Solutions of the Example-1}

We have taken first ten terms for approximate solution and we will verify that the tentative approximate solution is very closed to the exact solution and we will find absolute errors numerically comparing between the exact and the approximate solution by the above tables for different values of the parameter $\delta$. Table 1 shows absolute errors $\left|\mathrm{u}-\mathrm{u}_{\mathrm{app}}\right|$ for the value of parameter $\delta=4.45$ for $\mathrm{t}=1.1$ and table 2 shows the data for $\delta=3.5$ and $t=1$.

In these above tables, we have computed the absolute errors for the approximate solution at some values of $x \& t$. It seems that we can decrease the errors involving more terms with the approximate solution for other values of $\mathrm{x}$ and $\mathrm{t}$. These errors are for only a few terms in our approximation. So it is not a big problem. In this case we know the required solution is a closed form of a series, that is the solution is the sum of the infinite terms of components of approximate solutions, so if we involve more terms with the approximate solution $\mathrm{u}_{\mathrm{app}}$, we overcome this above problem and in spite of taking equal or unequal values of $\mathrm{x}$ and $\mathrm{t}$, we will get very small errors which shows our choice is efficiency. Using this procedure for sufficiently large values of n, we get a better approximation for the exact solution.

Figure 1, Figure 2 and Figure 3 show three-dimensional plots of the exact, the approximate and the error solutions respectively for space variable $\mathrm{x}$ belonging to the space interval $[-1.3,1.3]$ and for time variable $t$ belonging to the time interval $[1,1.1]$; i. e. $x \in[-1.3,1.3]$ and $t \in[1,1.1]$ for real value $\delta=4.45$ and similarly Figure 4, Figure 5 and Figure 6 show the exact, the approximate and the error solutions respectively for space variable $\mathrm{x} \in[-2.5,2.5]$ and time variable $t \in[1,1.1]$ for real value of $\delta=3.5$. Here in every cases the approximate solution is similar to the corresponding exact solution in their intervals. Outside of the aforesaid intervals the solutions are difference mutually. It is because of involving few terms with approximate solution. In the range $x \in[-1.3,1.3]$ Figure 7, Figure 8 and Figure 9 show two-dimensional graphs for exact, approximate and error solutions respectively for the values of $\mathrm{t}=1$ and $\delta=4.45$. The value $t=1$ is lower limit of the aforementioned range $t \in$ $[1,1.1]$ and the above value of $\delta=4.45$ is referred to in Table 1 and the aforesaid three-dimensional plots. The figures 7 and 8, exact and approximate solutions respectively, are decreasing near the intervals [-0.91887, 0.91887] and increasing out of the interval [-0.91887, 0.91887] in the domain $\mathrm{x} \in[-1.3,1.3]$. Similarly In the interval $\mathrm{x} \in[-2.5$, $2.5]$, the Figure 13 shows the combined graph of exact (solid curve) and approximate (dotted curve) solutions for $\mathrm{t}=1.05$ which is the mid-point of the aforesaid interval $[1,1.1]$ while the curves in Figure 13 are decreasing near the intervals [$1.30162,1.30162]$ and increasing out of the interval [$1.30162,1.30162]$. Also the combined curves coincide near the interval $[-2.5,2.5]$. One can see they are almost same over this interval and those has no difference between the exact and the approximate solutions because of their most similarity. Figures 10, 11 and 12 show the plots for exact, approximate and error solutions respectively while one can see the figures 10 and 11 are the same near the interval [-1.3, 1.3] for the upper limit of $t \in[1,1.1]$ with $\delta=4.45$. All the figures show that the results of the homotopy perturbation method are in approximate agreement with ADM. In figures$7,8,10,11$ and 13 the global maximums or amplitudes of oscillations are near 0.0658149, 0.0658149, 0.05501, 0.05501 and 0.272105 respectively and the global minimums are near $-0.0658149,-0.0658149,-0.05501,-0.05501$ and 0.272105 respectively.

\subsection{Example-2}

Consider the following nonlinear partial differential equation [7]

$$
\frac{\partial u}{\partial t}+e^{u} \frac{\partial u}{\partial x}-\left(\frac{\partial u}{\partial x}\right)^{2}-\frac{\partial^{2} u}{\partial x^{2}}-e^{-u}(1+x+t)=0,
$$

subject to the initial condition

$$
\mathrm{u}(\mathrm{x}, 0)=\ln \mathrm{x} .
$$

According to the homotopy perturbation method let us consider the following homotopy

$$
\begin{aligned}
& \mathrm{H}(\mathrm{V}, \mathrm{p})=(1- \\
& \mathrm{p})\left(\frac{\partial}{\partial \mathrm{t}} \mathrm{V}-\frac{\partial}{\partial \mathrm{t}} \mathrm{u}_{0}\right)+\mathrm{p}\left[\frac{\partial}{\partial \mathrm{t}} \mathrm{V}+\mathrm{e}^{\mathrm{V}} \frac{\partial}{\partial \mathrm{x}} \mathrm{V}-\left(\frac{\partial}{\partial \mathrm{x}} \mathrm{V}\right)^{2}-\frac{\partial^{2}}{\partial \mathrm{x}^{2}} \mathrm{~V}-\mathrm{e}^{-\mathrm{V}}(1+\mathrm{x}+\mathrm{t})\right]=0 \\
& \frac{\partial}{\partial \mathrm{t}} \mathrm{V}-\frac{\partial}{\partial \mathrm{t}} \mathrm{u}_{0}+\mathrm{p} \frac{\partial}{\partial \mathrm{t}} \mathrm{u}_{0}+\mathrm{pe}^{\mathrm{V}} \frac{\partial}{\partial \mathrm{x}} \mathrm{V}-\mathrm{p}\left(\frac{\partial}{\partial \mathrm{x}} \mathrm{V}\right)^{2}-\mathrm{p} \frac{\partial^{2}}{\partial \mathrm{x}^{2}} \mathrm{~V}-\mathrm{pe}^{-\mathrm{V}}(1+\mathrm{x}+\mathrm{t})=0,
\end{aligned}
$$


where $\mathrm{u}_{0}$ is the first initial approximation for the solution of (25), which satisfies the given initial condition (26) and selected by:

$$
\begin{gathered}
L(u)=\frac{\partial u}{\partial t}, N(u)=e^{u} \frac{\partial u}{\partial x}-\left(\frac{\partial u}{\partial x}\right)^{2}-\frac{\partial^{2} u}{\partial x^{2}}-e^{-u}(1+x+t) \\
\& f(r)=f(x, t)=0 .
\end{gathered}
$$

We can assume that the solution of (27) by HPM can be expressed as a power series in $\mathrm{p}$ as follows:

$$
\begin{aligned}
& \mathrm{V}=\sum_{\mathrm{i}=0}^{\infty} \mathrm{p}^{\mathrm{i}} \mathrm{V}_{\mathrm{i}}=\mathrm{V}_{0}+\mathrm{p} \mathrm{V}_{1}+\mathrm{p}^{2} \mathrm{~V}_{2}+\mathrm{p}^{3} \mathrm{~V}_{3}+\mathrm{p}^{4} \mathrm{~V}_{4}+\ldots \\
& \mathrm{p}^{2}: \frac{\partial \mathrm{V}_{2}}{\partial \mathrm{t}}+\mathrm{e}^{\mathrm{V}_{0}}\left(\frac{\partial \mathrm{V}_{1}}{\partial \mathrm{x}}+\mathrm{V}_{1} \frac{\partial \mathrm{V}_{0}}{\partial \mathrm{x}}\right)-2 \frac{\partial \mathrm{V}_{0}}{\partial \mathrm{x}} \cdot \frac{\partial \mathrm{V}_{1}}{\partial \mathrm{x}}-\frac{\partial^{2} \mathrm{~V}_{1}}{\partial \mathrm{x}^{2}}+\mathrm{e}^{-\mathrm{V}_{0}}(1+\mathrm{x}+\mathrm{t}) \mathrm{V}_{1}=0 \\
& \mathrm{p}^{3}: \frac{\partial \mathrm{V}_{3}}{\partial \mathrm{t}}+\frac{1}{2} \mathrm{e}^{\mathrm{V}_{0}}\left(2 \frac{\partial \mathrm{V}_{2}}{\partial \mathrm{x}}+2 \mathrm{~V}_{1} \frac{\partial \mathrm{V}_{1}}{\partial \mathrm{x}}+\mathrm{V}_{1}^{2} \frac{\partial \mathrm{V}_{0}}{\partial \mathrm{x}}+2 \mathrm{~V}_{2} \frac{\partial \mathrm{V}_{0}}{\partial \mathrm{x}}\right)-2 \frac{\partial \mathrm{V}_{0}}{\partial \mathrm{x}} \cdot \frac{\partial \mathrm{V}_{2}}{\partial \mathrm{x}}-\left(\frac{\partial}{\partial \mathrm{x}} \mathrm{V}_{1}\right)^{2}-\frac{\partial^{2} \mathrm{~V}_{2}}{\partial \mathrm{x}^{2}}-\frac{1}{2} \mathrm{e}^{-\mathrm{V}_{0}}(1+\mathrm{x}+\mathrm{t})\left(\mathrm{V}_{1}^{2}-2 \mathrm{~V}_{2}\right)=0 \\
& \mathrm{p}^{4}: \frac{\partial \mathrm{V}_{4}}{\partial \mathrm{t}}+\frac{1}{6} \mathrm{e}^{\mathrm{V}_{0}}\left(6 \frac{\partial \mathrm{V}_{3}}{\partial \mathrm{x}}+6 \mathrm{~V}_{1} \frac{\partial \mathrm{V}_{2}}{\partial \mathrm{x}}+3 \mathrm{~V}_{1}^{2} \frac{\partial \mathrm{V}_{1}}{\partial \mathrm{x}}+\mathrm{V}_{1}^{3} \frac{\partial \mathrm{V}_{0}}{\partial \mathrm{x}}+6 \mathrm{~V}_{2} \frac{\partial \mathrm{V}_{1}}{\partial \mathrm{x}}+6 \mathrm{~V}_{1} \mathrm{~V}_{2} \frac{\partial \mathrm{V}_{0}}{\partial \mathrm{x}}+6 \mathrm{~V}_{3} \frac{\partial \mathrm{V}_{0}}{\partial \mathrm{x}}\right) \\
& -2 \frac{\partial \mathrm{V}_{1}}{\partial \mathrm{x}} \cdot \frac{\partial \mathrm{V}_{2}}{\partial \mathrm{x}}-2 \frac{\partial \mathrm{V}_{0}}{\partial \mathrm{x}} \cdot \frac{\partial \mathrm{V}_{3}}{\partial \mathrm{x}}-\frac{\partial^{2} \mathrm{~V}_{3}}{\partial \mathrm{x}^{2}}+\frac{1}{6} \mathrm{e}^{-\mathrm{V}_{0}}(1+\mathrm{x}+\mathrm{t})\left(\mathrm{V}_{1}^{3}-6 \mathrm{~V}_{1} \mathrm{~V}_{2}+6 \mathrm{~V}_{3}\right)=0 \\
& \mathrm{p}^{5}: \frac{\partial \mathrm{V}_{5}}{\partial \mathrm{t}}+\frac{1}{24} \mathrm{e}^{\mathrm{V}_{0}}\left(24 \frac{\partial \mathrm{V}_{4}}{\partial \mathrm{x}}+24 \mathrm{~V}_{1} \frac{\partial \mathrm{V}_{3}}{\partial \mathrm{x}}+12 \mathrm{~V}_{1}^{2} \frac{\partial \mathrm{V}_{2}}{\partial \mathrm{x}}+4 \mathrm{~V}_{1}^{3} \frac{\partial \mathrm{V}_{1}}{\partial \mathrm{x}}+4 \mathrm{~V}_{1}^{4} \frac{\partial \mathrm{V}_{0}}{\partial \mathrm{x}}+24 \mathrm{~V}_{2} \frac{\partial \mathrm{V}_{2}}{\partial \mathrm{x}}\right. \\
& \left.+24 \mathrm{~V}_{1} \mathrm{~V}_{2} \frac{\partial \mathrm{V}_{1}}{\partial \mathrm{x}}+12 \mathrm{~V}_{1}^{2} \mathrm{~V}_{2} \frac{\partial \mathrm{V}_{0}}{\partial \mathrm{x}}+12 \mathrm{~V}_{2}^{2} \frac{\partial \mathrm{V}_{0}}{\partial \mathrm{x}}+24 \mathrm{~V}_{3} \frac{\partial \mathrm{V}_{1}}{\partial \mathrm{x}}+24 \mathrm{~V}_{1} \mathrm{~V}_{3} \frac{\partial \mathrm{V}_{0}}{\partial \mathrm{x}}+24 \mathrm{~V}_{4} \frac{\partial \mathrm{V}_{0}}{\partial \mathrm{x}}\right) \\
& -2 \frac{\partial \mathrm{V}_{1}}{\partial \mathrm{x}} \cdot \frac{\partial \mathrm{V}_{3}}{\partial \mathrm{x}}-2 \frac{\partial \mathrm{V}_{0}}{\partial \mathrm{x}} \cdot \frac{\partial \mathrm{V}_{4}}{\partial \mathrm{x}}-\left(\frac{\partial}{\partial \mathrm{x}} \mathrm{V}_{2}\right)^{2}-\frac{\partial^{2} \mathrm{~V}_{4}}{\partial \mathrm{x}^{2}}+\frac{1}{24} \mathrm{e}^{-\mathrm{V}_{0}}(1+\mathrm{x}+\mathrm{t})\left(\mathrm{V}_{1}^{4}-12 \mathrm{~V}_{1}^{2} \mathrm{~V}_{2}+12 \mathrm{~V}_{2}^{2}+24 \mathrm{~V}_{1} \mathrm{~V}_{3}-24 \mathrm{~V}_{4}\right)=0
\end{aligned}
$$

By the HPM, the approximate solution of (25), therefore,

$$
\mathrm{u}=\lim _{\mathrm{p} \rightarrow 1} \mathrm{~V}=\mathrm{V}_{0}+\mathrm{V}_{1}+\mathrm{V}_{2}+\mathrm{V}_{3}+\mathrm{V}_{4}+\mathrm{V}_{5}+\cdots \cdots
$$

Now substituting (28) into (27) and equating the coefficients of the like terms with the identical powers of $p$ leads to the following equations:

$$
\mathrm{p}^{0}: \frac{\partial}{\partial \mathrm{t}} \mathrm{V}_{0}-\frac{\partial}{\partial \mathrm{t}} \mathrm{v}_{0}=0
$$

and so on.

Solving the above equations (31-35) and finding the unknown solution $u(x, t)$, we take the initial guess $V_{0}(x, t)=u_{0}(x, t)=$ $\ln x$ which satisfies the given initial condition (26) of (25) and using the initial conditions $V_{n}=0$ at $t=0,1 \leq n \in N$ for all $(31$ 35), we get from (31).

$$
\mathrm{V}_{1}=\frac{1}{2 \mathrm{x}}\left(2 \mathrm{t}+\mathrm{t}^{2}\right)
$$

Again putting the values of $\mathrm{V}_{0}, \mathrm{~V}_{1}$ into (32), we get

$$
V_{2}=\frac{-1}{24 x^{2}}\left(12 t^{2}+12 t^{3}+3 t^{4}+12 t^{2} x+4 t^{3} x\right)
$$

Similarly, we get from the other equations (33-35),

$$
\begin{gathered}
V_{3}=\frac{1}{24 x^{3}} t^{3}\left(8+12 t+6 t^{2}+t^{3}+12 x+10 t x+2 t^{2} x+4 x^{2}+t x^{2}\right), \\
V_{4}=\frac{-1}{2880 x^{4}}\left(720 t^{4}+1440 t^{5}+1080 t^{6}+360 t^{7}+45 t^{8}+1440 t^{4} x+1920 t^{5} x+\right. \\
\left.840 t^{6} x+120 t^{7} x+840 t^{4} x^{2}+600 t^{5} x^{2}+100 t^{6} x^{2}+120 t^{4} x^{3}+24 t^{5} x^{3}\right), \\
V_{5}=\frac{1}{1440 x^{5}}\left(288 t^{5}+720 t^{6}+720 t^{7}+360 t^{8}+90 t^{9}+9 t^{10}+720 t^{5} x+1320 t^{6} x\right. \\
+900 t^{7} x+270 t^{8} x+30 t^{9} x+600 t^{5} x^{2}+720 t^{6} x^{2}+280 t^{7} x^{2}+35 t^{8} x^{2} \\
\left.+180 t^{5} x^{3}+112 t^{6} x^{3}+16 t^{7} x^{3}+12 t^{5} x^{4}+2 t^{6} x^{4}\right),
\end{gathered}
$$

and so on.

Therefore putting the values of $V_{0}, V_{1}, V_{2}, V_{3}, V_{4}, V_{5}$ into (29) and after arranging the terms as a power series to the order of $\mathrm{t}^{\mathrm{n}}$ where $\mathrm{n}=0,1,2,3,4,5$, we get an approximate solution in a series form of (25) 


$$
\begin{gathered}
u_{a p p}=V_{0}+V_{1}+V_{2}+V_{3}+V_{4}+V_{5}+\ldots \ldots \ldots \\
=\ln x+\frac{1}{2 x}\left(2 t+t^{2}\right)-\frac{1}{24 x^{2}}\left(12 t^{2}+12 t^{3}+3 t^{4}+12 t^{2} x+4 t^{3} x\right)+ \\
\frac{1}{24 x^{3}} t^{3}\left(8+12 t+6 t^{2}+t^{3}+12 x+10 t x+2 t^{2} x+4 x^{2}+t x^{2}\right)- \\
\frac{1}{2880 x^{4}}\left(720 t^{4}+1440 t^{5}+1080 t^{6}+360 t^{7}+45 t^{8}+1440 t^{4} x+1920 t^{5} x+840 t^{6} x+120 t^{7} x\right. \\
\left.+840 t^{4} x^{2}+600 t^{5} x^{2}+100 t^{6} x^{2}+120 t^{4} x^{3}+24 t^{5} x^{3}\right)+ \\
\frac{1}{1440 x^{5}}\left(288 t^{5}+720 t^{6}+720 t^{7}+360 t^{8}+90 t^{9}+9 t^{10}+720 t^{5} x+1320 t^{6} x+900 t^{7} x\right. \\
+270 t^{8} x+30 t^{9} x+600 t^{5} x^{2}+720 t^{6} x^{2}+280 t^{7} x^{2}+35 t^{8} x^{2}+ \\
\left.180 t^{5} x^{3}+112 t^{6} x^{3}+16 t^{7} x^{3}+12 t^{5} x^{4}+2 t^{6} x^{4}\right)+\cdots \cdots \cdots \\
=\ln x+\frac{1}{x} t-\frac{1}{2 x^{2}} t^{2}+\frac{1}{3 x^{3}} t^{3}-\frac{1}{4 x^{4}} t^{4}+\frac{1}{5 x^{5}} t^{5}-\frac{1}{6 x^{6}} t^{6}+\cdots \cdots
\end{gathered}
$$

Therefore the above approximate solution yields the closed form

$$
\mathrm{u}(\mathrm{x}, \mathrm{t})=\ln (\mathrm{x}+\mathrm{t})
$$

Which is the exact solution (36) and also which is the same solution of nonlinear partial differential equation (25) that was achieved by the Adomian Decomposition Method (ADM) [7] for the same initial condition (26).

\subsubsection{Graphical Representations}

We first represent some three-dimensional diagrams and later show two-dimensional diagrams for the exact solution.

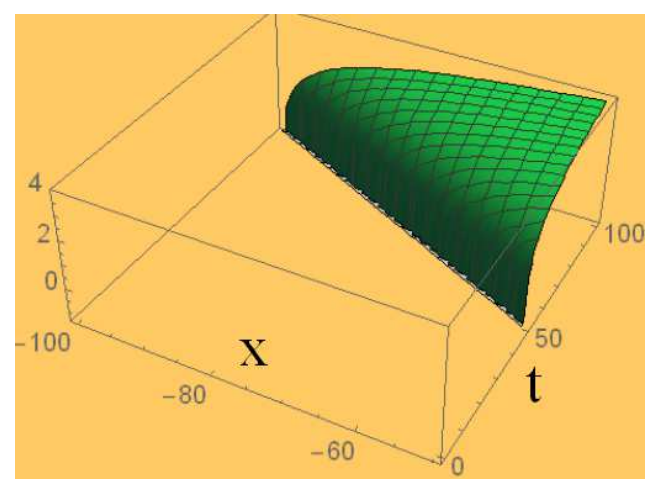

Figure 15. Exact Solution $x \in[-100,-50]$ and $t \in[0,100]$.

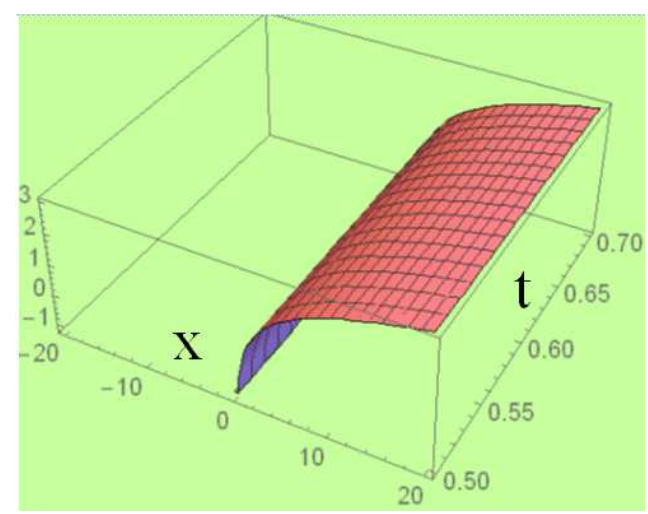

Figure 16. Exact Solution $x \in[-20,20]$ and $t \in[0.5,0.7]$.

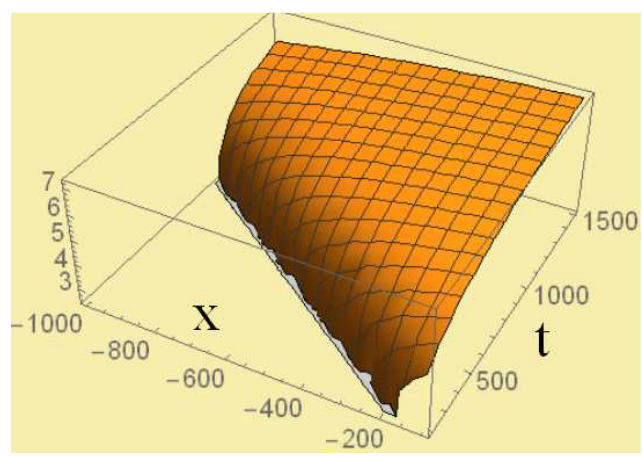

Figure 17. Exact Solution $x \in[-1000,-100]$ and $t \in[200,1500]$.

Now we show some two-dimensional plots of exact solution for $\mathrm{t}=100,0.7$ and 1500 .

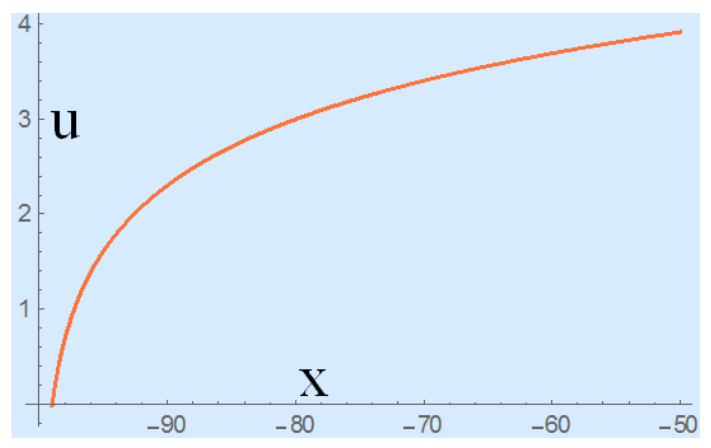

Figure 18. $x \in[-100,-50]$ and $t=100$

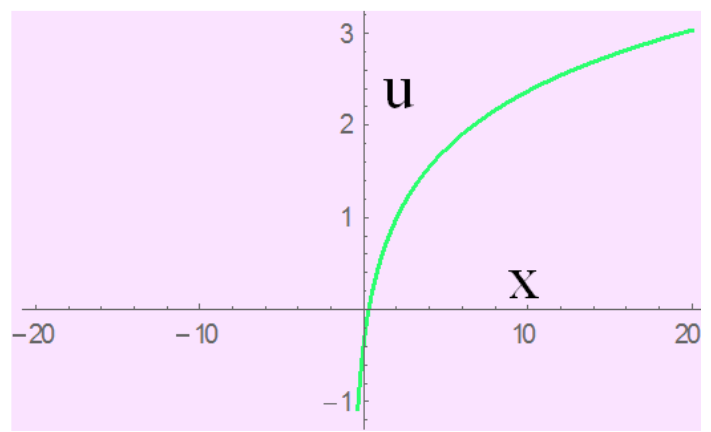

Figure 19. $x \in[-20,20]$ 


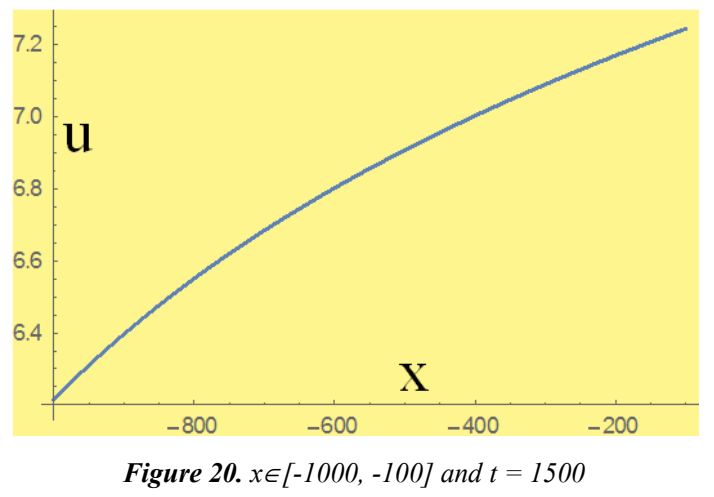

\subsubsection{Result and Discussions of the Exact Solution of the Example-2}

Various plots obtained by HPM are shown in Figure 15, Figure 16, Figure 17, Figure 18, Figure 19 and Figure 20. Figure 15, Figure 16 and Figure 17 show three- dimensional plots for different ranges of $\mathrm{x}$ and $\mathrm{t}$ while Figure 18, Figure 19 and Figure 20 show two- dimensional plots. Figure 15 and Figure 18 show three-dimensional and two-dimensional plots respectively for the same range of $\mathrm{x} \in[-100,-50]$ whereas Figure 15 shows the solution for $t \in[0,100]$ and Figure 18 shows for $\mathrm{t}=100$ which is the end point of the interval $t \in[0$, 100]. Figure 16 and Figure 19 show three-dimensional and two-dimensional plots respectively for the same range of $\mathrm{x} \in[-20,20]$ whereas Figure 16 shows the solution for $\mathrm{t} \in[0.5$, $0.7]$ and Figure 19 shows 2D solution for $\mathrm{t}=0.7$ which is the end point of the interval $t \in[0.5,0.7]$. Similarly Figure 17 and Figure 20 show three-dimensional and two-dimensional plots respectively for the same range of $x \in[-1000,-100]$ whereas Figure 17 shows the exact solution for $t \in[200,1500]$ and Figure 20 shows $2 \mathrm{D}$ figure for $\mathrm{t}=1500$ which is the end point of the aforesaid interval $t \in[200,1500]$ of the Figure 17. We see that real solutions are not present at every lower limit of all ranges of $\mathrm{x}$ and the values of the solution of all threedimensional figures in different ranges of $\mathrm{x}$ and $\mathrm{t}$ are maximum at the endpoints of every interval of $x$ and $t$. In all two- dimensional figures for all ranges of $\mathrm{x}$, we see that the solutions are increasing into the aforesaid intervals of $\mathrm{x}$ for the fixed values of $t$. In figures 18, 19 and 20 the local or the global maximums are 3.91202, 3.03013 and 7.24423 respectively in their respective intervals.

\section{Conclusion}

In this thesis work homotopy perturbation method is used to solve nonlinear differential equation. Figures and tables show that the comparison between the exact and approximate solutions. It can be seen that the approximate solution obtained by HPM is closed to the exact solution. The HPM has an advantage over the ADM which is that it solves the nonlinear problems without using Adomian polynomials. Our earned results have been approved the efficiency and the ability of this method for solving these problems. This method solves the problem without any need for discretization of the variables. Therefore it is not effected by computation round-off errors and one is not faced with the necessity for large computer memory and time. In addition the calculations involved in HPM are very simple and straight forward. The method avoids the difficulties and massive computational work that usually arise from other classical methods.

\section{References}

[1] M. Esmaeilpour, D. D. Ganji, Application of He's homotopy perturbation method to boundary layer flow and convection heat transfer over a flat plate, Physics Letters A, 372, 33-38, Iran, (2007).

[2] J. H. He, Application of homotopy perturbation method to nonlinear wave equations; Chaos, Solitons and Fractals, 26 (3), 695-700, (2005).

[3] G. Adomian. Solving Frontier Problems of Physics: The Decomposition Method. Kluwer Academic Publishers, Boston, (1994).

[4] M. Wazwaz. Adomian decomposition method for a reliable treatment of the Bratu-type equations. Applied Mathematics and Computation, 166: 652-663, (2005).

[5] D. D. Ganji, H. Tari, M. Bakhshi Jooybari, Variational iteration method and homotopy perturbation method for nonlinear evolution equations, International Journal of Computational and Applied Mathematics, 54, 1018- 1027, (2007).

[6] Mario Basto, Viriato Semiao, Francisco L. Calheiros. Numerical study of modified Amomian's method applied to Burger's Equation. Journal of Computational and Applied Mathematics, 206, 927-949, (2007).

[7] Doğan Kaya, The use of Adomian decomposition method for solving a specific nonlinear partial differential equations, Bulletin of the Belgian Math. Soc., Research Gate, 9, 343-349, (2002).

[8] Fatheah Ahmad Alhendi, Aisha Abdullah Alderremy, Numerical Solutions of Three- Dimensional Coupled Burgers' Equations by Using Some Numerical Methods, Journal of Applied Mathematics and Physics, 4, 2011-2030, Saudi Arabia, (2016).

[9] J. H. He, “Approximate analytical solution for seepage flow with fractional derivatives in porous media," Comput. Methods Appl. Mech. Engrg., vol. 167, pp. 57-68, (1998).

[10] J. H. He, A coupling method of homotopy technique and perturbation technique for nonlinear problems, International Journal of Non-Linear Mechanics, 35 (1), 37-43, (2000).

[11] J. H. He, Comparsion of homotopy perturbation method and homotopy analysis method, Applied Mathematics and Computation, 156, 527-539, (2004).

[12] J. Biazar, H. Ghazvini, Convergence of the homotopy perturbation method for partial differential equations, Non Linear Anal. RWA, (2008).

[13] M. Tahmina Akter, A. S. M. Moinuddin and M. A. Mansur Chowdhury, Semi-Analytical Approach to Solve NonLinear Differential Equations and Their Graphical Representations, International Journal of Applied Mathematics and Statistical Science, Vol. 3, Issue 1, 35-56, India, (2014). 
[14] M. Tahmina Akter and M. A. Mansur Chowdhury, Homotopy Perturbation Method for Solving Nonlinear Partial Differential Equations, IOSR Journal of Mathematics, Vol. 12, Issue 5, Ver. VI, PP 59-69, (2016), India.

[15] J. Biazar, M. Eslami, H. Ghazvini, Homotopy perturbation method for systems of partial differential equations, International Journal of Nonlinear Sciences and Numerical Simulation.

[16] O. Abdul Aziz, I. Hashim, S. Momani, Application of homotopy perturbation method to fractional IVPs, J. Comput. Appl. Math., 216 (2), pp. 574-584, (2008).

[17] Shaher Momani, Zaid Odibat, Homotopy perturbation method for nonlinear partia differential equations of fractional order, Physics Letters A, 365, 345-350, (2007).

[18] J. H. He. Homotopy perturbation technique. Computer methods in Applied Mechanics and Engineering, vol. 178, pp. 257-262, (1999).

[19] J. H. He, Homotopy perturbation method: a new nonlinear analytical technique, Applied Mathematics and Computation, 135, pp. 73-79, (2003)

[20] J. H. He, The homotopy perturbation method for nonlinear oscillators with discontinuities, Applied Mathematics and Computation, 151, 287-290, (2004).

[21] J. H. He, Periodic solutions and bifurcations of delaydifferential equations, Phys. Lett. A 374 (4-6), 228-230, (2005).
[22] J. H. He, Homotopy perturbation method for solving boundary value problems, Physics Letters A 350 (1-2), 87-88, (2006).

[23] Desai, K. R. and Pradhan, V. H., Solution of Burger's Equation and Coupled Burger's Equations by Homotopy Perturbation Method, International Journal of Engineering, Re- search and Applications, 2, 2033-2040, (2012).

[24] Y. Cherruault and G. Adomian. Decomposition methods: a new proof of convergence. Math. Comput. Modelling, 8, 103106, (1993).

[25] G. Adomian, A new approach to the heat equation-an application of the Decomposition method, J. Math. Anal. Appl., 113, 202-209, (1986).

[26] A. M. Wazwaz, A Reliable Modification of Adomian Decomposition method, Appl. Math. Comp., 102, 77-86 (1999).

[27] J.-L. Li, "Adomian's decomposition method and homotopy perturbation method in solving nonlinear equations," Journal of Computational and Applied Mathematics, vol. 228, no. 1, pp. 168-173, 2009.

[28] T. Öziş and A. Yıldırım, "Comparison between Adomian's method and He's homotopy perturbation method," Computers \& Mathematics with Applications, vol. 56, no. 5, pp. 12161224, 2008.

[29] L. Cveticanin, "Homotopy-perturbation method for pure nonlinear differential equation," Chaos Solitons \& Fractals, vol. 30, no. 5, pp. 1221-1230, (2006). 